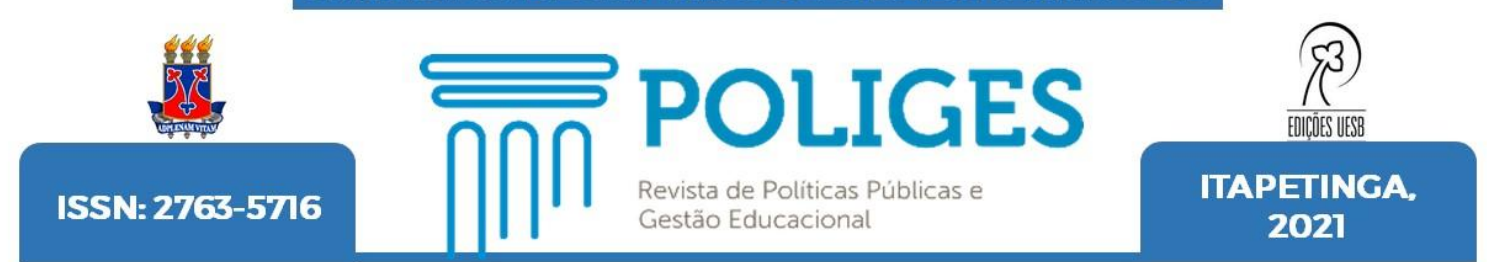

\title{
GESTÃO ESCOLAR, TRABALHO PEDAGÓGICO E EDUCAÇÃO DO CAMPO: ANÁLISE DE UM CONTEXTO
}

\author{
SCHOOL MANAGEMENT, PEDAGOGICAL WORK AND FIELD EDUCATION: ANALYSIS \\ OF A CONTEXT
}

GESTIÓN ESCOLAR, TRABAJO PEDAGÓGICO Y EDUCACIÓN DE CAMPO: ANÁLISIS DE CONTEXTO

\begin{abstract}
Terciana Vidal Moura
https://orcid.org/0000-0003-3772-7724

Universidade Federal do Recôncavo Baiano (UFRB) - Brasil

Juliane Queiróz Muniz Neri

https://orcid.org/0000-0001-5424-7365

Universidade Federal do Recôncavo Baiano (UFRB) - Brasil
\end{abstract}

DOI: 10.22481/poliges.v2i1.8516

Resumo: A Educação do Campo vem conquistando um lugar de destaque na agenda das políticas públicas, inaugurando um outro olhar sobre o campo. O Movimento Por uma Educação do Campo é fruto do acúmulo de diversas experiências políticas, educativas e pedagógicas construídas historicamente pelo conjunto de movimentos populares do Brasil. A Educação do Campo apresenta-se como um paradigma transformador da sociedade que visa à emancipação dos sujeitos, à superação das relações de trabalho excludentes e produção de uma existência humana digna. Desse modo, a epistemologia da Educação do Campo vai exigir a transformação da escola, principalmente quanto à Gestão da escola/democratização do espaço escolar. Nesse sentido, o presente texto tem como foco trazer reflexões sobre a gestão escolar no cotidiano das escolas do campo. Traz um recorte de pesquisas finalizadas e em andamento vinculadas ao Grupo de Pesquisa Observale, Grafho e ao Mestrado Profissional em Educação do Campo da UFRB.

Palavras-chave: Educação do Campo. Gestão Escolar. Trabalho Pedagógico

\begin{abstract}
Field Education has been gaining a prominent place on the public policy agenda, inaugurating another view of the countryside. The Movement for a Field Education is the result of the accumulation of diverse political, educational and pedagogical experiences historically built by the group of popular movements in Brazil. Field Education presents itself as a transformative paradigm of society that aims at the emancipation of subjects, the overcoming of exclusive working relationships and the production of a dignified human existence. In this way, the epistemology of Field Education will demand the transformation of the school, especially regarding school management / democratization of the school space. In this sense, the present text focuses on bringing reflections on school management in the daily life of field schools. It brings a snapshot of completed and ongoing research linked to the Observale, Grafho Research Groups and the Professional Master in Field Education at UFRB.
\end{abstract}

Keywords: Field Education. School management. Pedagogical Work 
Resumen: La Educación del Campo esta logrando un lugar destacado en la agenda de políticas públicas, inaugurando otra mirada al campo. El Movimiento por la Educación del Campo es el resultado de la acumulación de diversas experiencias políticas, educativas y pedagógicas construidas históricamente por el grupo de movimientos populares en Brasil. La Educación del Campo se presenta como un paradigma transformador de la sociedad que apunta a la emancipación de los sujetos, la superación de las relaciones laborales exclusivas y la producción de una existencia humana digna. De esta manera, la epistemología de la Educación del Campo demandará la transformación de la escuela, especialmente en lo que se refiere a la gestión escolar / democratización del espacio escolar. En este sentido, el presente texto se centra en traer reflexiones sobre la gestión escolar en la vida cotidiana de las escuelas rurales. Aporta una instantánea de la investigación finalizada y en curso vinculada a los Grupos de Investigación Observale, Grafho y al Máster Profesional en Educación Rural de la UFRB.

Palabras clave: Educación del Campo. Gestión escolar. Trabajo pedagógico

\section{Introdução}

A Educação do Campo vem conquistando um lugar de destaque na agenda das políticas públicas, inaugurando um outro olhar sobre o campo. O Movimento Por uma Educação do Campo é fruto do acúmulo de diversas experiências políticas, educativas e pedagógicas construídas historicamente pelo conjunto de movimentos populares do Brasil que, desde a época do Brasil-Colônia, mobilizam-se na construção de alternativas ao modelo de sociedade excludente, que secularmente têm marcado o país. Constitui-se num projeto de luta política que tem como premissa fundamental a construção de um projeto de desenvolvimento para o campo brasileiro que venha romper com a herança de nosso processo civilizatório que produziu uma sociedade fundada em valores oligárquicos e um sistema de produção que alimentou e legitimou secularmente a concentração fundiária, controlando de forma seletiva o acesso à propriedade da terra às populações campesinas.

O projeto hegemônico, implementando historicamente ao longo de séculos na sociedade brasileira, sofreu contestações em diferentes momentos, pelos sujeitos excluídos. Santos (2013, p. 35) sublinha que desde os primórdios de nossa colonização é possível se destacar movimentos contra opressão e dominação, protagonizados pelos indígenas, pelos negros escravizados, pelos quilombos, bem como diversas iniciativas e lutas pela nossa independência. Para a autora, "Basta recorrer à história brasileira para ter conhecimento do grande contingente de pessoas que se uniram em torno de objetivos comuns, constituindo assim, os movimentos sociais do Brasil".

A história do campesinato brasileiro mostra que historicamente o camponês foi excluído enquanto identidade social e da participação política do pacto político da 
sociedade brasileira. Para Martins (1986), trata-se de uma exclusão ideológica "tão profunda e tão radical, que alguns dos mais importantes acontecimentos políticos da história do Brasil são camponeses" (MARTINS, 1986, p. 25), revelando, assim, uma forte reação política dos excluídos, ainda que nem sempre de forma organizada e sistemática. Nesse sentido, Silva (2006, p. 64) vem ressaltar que "Esse resgate histórico se faz necessário num país onde cada vez mais se descarta o passado, mais rapidamente perde-se a visão de totalidade, da tradição camponesa como pilar da identidade dos povos do campo". Ainda para Martins (1986), é preciso inserir o protagonismo do camponês e dos movimentos por ele liderados na história oficial. Quanto a isso, Maria Socorro Silva afirma que

[...] os movimentos sociais do campo vêm se constituindo ao longo da nossa história, como um espaço de compreensão e luta da realidade camponesa, de conhecimento e (re)conhecimento dos saberes, cultura e dos direitos dos sujeitos do campo, de produção de uma teoria e uma prática pedagógica, por isso, que sentimos necessidade de recuperar a memória no sentido de identificar os diferentes ensinamentos que essas iniciativas construíram ao longo da nossa história. (SILVA, 2006, p. 60).

Destarte, Martins (1986) sublinha que a história brasileira precisa se libertar de seu caráter eminentemente urbano, quando veicula a visão de mundo somente daqueles que participam do pacto político. Movimentos como os quilombos, Canudos (1893-1897), a Guerra do Contestado, ocorrido entre 1912-1916, no Sul do Brasil, a Revolta do Formoso, ocorrida na década de 1950, no estado de Goiás, as Ligas Camponesas, nas décadas de 1940-1960, no Nordeste, dentre outros, foram importantes no processo de ocupação no campo político, social e educacional dentro do Estado e da sociedade pelos camponeses (MARTINS, 1989). Desse modo, trabalhar no sentido de recuperar a "memória histórica" dos movimentos do campo contribui para "o resgate dos fundamentos e a socialização das práticas existentes que evidenciam elementos e dimensões que estiveram presentes nas práticas da educação popular" (SILVA, 2006, p. 61).

Portanto, a Educação do Campo vai de encontro ao modelo de desenvolvimento hegemônico que privilegiou/privilegia historicamente os interesses dos grandes proprietários de terra no Brasil e, portanto, está intrinsecamente imbricado a um projeto de educação da classe trabalhadora. Apresenta-se como um paradigma transformador da sociedade que visa à emancipação dos sujeitos, à superação das relações de trabalho excludentes e à produção de uma existência humana digna. 
Desse modo, a epistemologia da Educação do Campo vai exigir a transformação da escola em vários aspectos e dimensões, aqui destacamos a gestão da escola na perspectiva da democratização do espaço escolar. Nesse sentido, o presente texto tem como foco trazer reflexões sobre a gestão escolar no cotidiano das escolas do campo. Traz um recorte de pesquisas finalizadas ${ }^{1}$ e em andamento ${ }^{2}$, vinculadas aos Grupos de Pesquisa Observatório da Educação do Campo no Recôncavo e Vale do Jiquiriçá/BA (Observale), Grupo de Pesquisa (Auto)biografia, Formação e História Oral (GRAFHO ${ }^{3}$ e ao Mestrado Profissional em Educação do Campo da UFRB (PPGEDUCAMPO).

O presente texto tem como objetivo geral refletir sobre os processos de gestão escolar vivenciados nas escolas do campo do Sistema Municipal de Ensino de um dos municípios da Bahia e a sua relação com o trabalho pedagógico desenvolvido pelos professores que atuam nessas escolas. Defendemos que uma gestão escolar democrática deve motivar toda a comunidade na união em prol do desenvolvimento da unidade escolar, justamente porque, a identidade da escola do campo, dá-se a partir de sua relação intrínseca com questões inerentes à sua realidade e concebe os sujeitos do campo como protagonistas e construtores de políticas públicas.

Metodologicamente, constituiu-se num Estudo de Caso qualitativo. Teve como universo de pesquisa as Escolas do Campo que integram o Sistema Municipal de Ensino de um dos municípios do Estado da Bahia-Brasil. Como sujeitos, participaram desta investigação professores, alunos, Direção e Coordenação dessas escolas. Como procedimentos para o levantamento de dados, foram utilizados a pesquisa bibliográfica, a pesquisa documental e a pesquisa de campo; e foram empregadas as seguintes técnicas de pesquisa: observação, aplicação de questionário, realização de entrevistas semiestruturadas, grupo focal e técnica de representação por desenho.

A Educação do Campo vem conquistando um lugar de destaque na agenda política nas esferas municipais, estaduais e federais nos últimos anos, tornando-se uma nova concepção de Campo, onde os camponeses vêm fortalecendo a classe na luta por outra educação, a qual valoriza os conhecimentos das práticas sociais dos camponeses e destaca o Campo como lugar de trabalho, moradia, lazer, identidade, sociabilidade, e por

\footnotetext{
${ }^{1}$ A gestão do trabalho pedagógico dos professores do campo no contexto das políticas educacionais de regulação. Tese de Doutoramento em Ciências da Educação, Especialidade em Organização e Administração Escolar, pela Universidade do Minho de autoria da Profa. Dra. Terciana Vidal Moura (UFRB). ${ }^{2}$ A GESTÃO DAS ESCOLAS DO CAMPO NOS MUNICÍPIOS DO VALE DO JIQUIRIÇÁ: APROXIMAÇÕES, DISTANCIAMENTO E PROPOSIÇÕES. Pesquisa em andamento da mestranda Juliane Queiróz Muniz Neri, PPGEDUCAMPO/UFRB..

${ }^{3}$ MULTISSERIAÇÃO E TRABALHO DOCENTE: DIFERENÇAS, COTIDIANO ESCOLAR E RITOS DE PASSAGEM, Projeto de Pesquisa coordenado pelo Prof. Dr. Elizeu Clementino, de Souza (UNEB).
} 
que não, lugar de construção de novas possibilidades de produção social e desenvolvimento.

Como fruto do acúmulo de diversas experiências políticas, educativas e pedagógicas construídas historicamente pelo conjunto de movimentos populares do Brasil, a Educação do Campo apresenta-se como um paradigma transformador da sociedade que visa à emancipação dos sujeitos, à superação das relações de trabalho excludentes e à produção de uma existência humana digna. Esse projeto conflita o paradigma neoliberal que tem orientado as políticas educacionais brasileiras e aponta um referencial de mundo que vê a educação como prática social e caminha no sentido de transformação da realidade produzida pela barbárie do capital, a partir de projetos de emancipação social.

Nesse sentido, a Educação do Campo, ao se nutrir de concepções pedagógicas críticas e políticas, fundamenta-se numa epistemologia que se opõe às tendências e concepções que têm embalado as políticas educacionais brasileiras contemporâneas, principalmente aquelas que orientam a formação docente e a gestão e organização do trabalho pedagógico por estarem alicerçadas epistemologicamente pela lógica neoliberal.

Destarte, os sujeitos do campo aperceberam-se da imperiosa necessidade de transformar a escola nos diferentes espaços rurais do Brasil, considerando que a escola que está posta e a educação ofertada aos sujeitos do campo não atendem às suas especificidades educacionais. Dessa forma, Caldart (2004, p. 23) tem alertado que "Compreender o lugar da escola na Educação do Campo é ter claro que ser humano ela precisa ajudar a formar". Maria Socorro Silva (2008), a partir do estudo e da análise do percurso histórico dos movimentos sociais e especificamente dos movimentos sociais do campo, vem afirmar a existência de uma Teoria Pedagógica construída pela ação pedagógica dos movimentos sociais que inauguraram, na tradição pedagógica brasileira, um jeito específico de promover a educação dos povos do campo.

Desse modo, a Educação do Campo vai exigir a transformação da escola e, consequentemente, da concepção de gestão da escolar, apontando a gestão democratização do espaço escolar como horizonte. A lógica pensada a partir desse projeto de sociedade e de educação, traz inúmeros desafios e demandas à gestão do trabalho pedagógico da escola, que deve estar fundado na epistemologia e nas formas defendidas por esse projeto, trazendo implicação também para a configuração do trabalho docente, buscando alternativas para uma escola de qualidade, que apontem 
para a democracia como um processo indispensável para um bom desenvolvimento na comunidade escolar.

\section{Educação do Campo e Gestão escolar}

O Projeto Político-Pedagógico da Educação do Campo também tem colocado desafios à gestão escolar na perspectiva de que ela necessariamente precisa estar vinculada a uma concepção de gestão mais afinada com a sua epistemologia, pois, segundo José Carlos Libâneo et al. (2012), a escola como uma instituição social responde a determinados objetivos, vinculados a um determinado modelo de sociedade, como bem explicitam os autores:

A definição - dos objetivos educacionais decorre de demandas e exigências econômicas políticas, sociais e culturais que a sociedade apresenta às escolas, do desenvolvimento da pesquisa científica em questões educacionais e do ensino, das necessidades sociais e pessoais dos alunos relativas a conhecimentos práticas culturais, mercado de trabalho, exercício da cidadania etc. (2012, p. 425).

Portanto, para atingir as suas finalidades educacionais, a escola, enquanto instituição, precisa favorecer condições organizacionais para sua materialização nos processos ensino-aprendizagem. Mudar as relações sociais e, principalmente, as relações de poder dentro da escola exige em primeira instância, uma mudança radical nos padrões culturais que regem esse espaço, pois, segundo Lima (2010, p. 09),

O caráter complexo da escola como organização educativa formal e aparelho administrativo indispensável à realização de uma política educativa escolar contrasta, assim, com as focalizações de tipo predominantemente normativo e prescritivo que, ao longo de muitas décadas, vem contribuindo para a naturalização e a reprodução de um dado modelo de escola.

Desse modo é que a Educação do Campo, enquanto um paradigma de sociedade emancipatório, refuta a concepção de gestão assentada em princípios capitalistas - já que nega a forma como produz e (re)produz as relações sociais e a desigualdades entre as classes socais - e aposta em uma concepção de gestão, primeiramente, que respeite ao "locus escolar nos quais as práticas de gestão são efetuadas [...] a participação da comunidade escolar", como também, reconheça as especificidades da educação, escola e sujeitos do campo para que esses elementos sejam incorporados às práticas de gestão 
das escolas e com isso "evidenciar os elementos específicos de uma gestão democrática das escolas do campo e sua contribuição para um sistema efetivamente democrático" (MARTINS, 2009, p. 3), já que, a concepção de educação e de escola defendida pelo Projeto Político-Pedagógico da Educação do Campo coloca-as como projetos e construções coletivas, dos sujeitos e com os sujeitos e não para os sujeitos.

Como construção coletiva, implica uma concepção de gestão coerente com essa assertiva, aqui concebida como "gestão participativa democrática". Trazemos aqui para defini-la um conceito de Paro (2010), pois defendemos ser aquele que mais coaduna com a concepção de gestão escolar na perspectiva da Educação do Campo:

Administração escolar inspirada na cooperação recíproca entre os homens deve ter como meta a constituição, a escola, de um novo trabalhador coletivo, que sem constrangimento da gerência capitalista e da parcelarização desumana do trabalho, seja uma decorrência do trabalho cooperativo de todos os envolvidos no processo escolar guiados por uma vontade coletiva, em direção ao alcance dos objetivos verdadeiramente educacionais da escola. Aí, a utilização tanto dos recursos materiais e conceptuais - por meio da racionalização do trabalho- quanto do esforço humano coletivo - pela coordenação - se dará não mais de forma autoritária e exploradora do trabalho alheio, mas de maneira que, dominando os elementos naturais que the são postos à disposição, o homem, por sua ação em colaboração recíproca e solidária com os outros homens, possa reafirmar sua autenticidade humana, no trabalho realizado de forma socais, mas efetivamente livre (PARO, 2010, p. 210).

A gestão escolar nas escolas do campo vem trabalhando no sentido de que todos se sintam e façam parte do projeto de escola, que a partir de um trabalho coletivo, rompam com a divisão social do trabalho e a alienação pelo trabalho, impostas pela concepção de administração escolar e modos de produção capitalista, que o trabalho educacional seja concebido por sua dimensão coletiva na perspectiva de Paulo Freire, em que "ninguém educa ninguém, ninguém se educa a si mesmo, os homens se educam entre si, mediatizados pelo mundo" (1982, p. 79) e, por um "processo pelo qual o homem apropria-se da natureza, domina-a submete-a a sua vontade, domina-a em seu proveito, para produzir sua existência material” (MARX apud PARO, 2010, p. 27). Ao fazer isso, o homem, além de transformar a natureza, também transforma a si mesmo. Essa perspectiva de gestão democrática e participativa coloca o homem do campo como sujeito histórico, autônomo e construtor dos caminhos de sua vida. 
Ademais, as Diretrizes Operacionais para a Educação Básica nas Escolas do Campo (2002), ancoradas na epistemologia do Projeto Político e Pedagógico da Educação do Campo, trazem marcos e definições importantes que fortalecem a construção da Educação do Campo e legitima, no âmbito legal, a construção de outras políticas educacionais voltadas para essa especificidade e projeto, tais como:

-A identidade da escola do campo. O Art. $2^{\circ}$, Parágrafo Único, estabelece que a identidade da escola do campo "é definida pela sua vinculação às questões inerentes à sua realidade, ancorando-se na temporalidade e saberes próprios dos estudantes, na memória coletiva que sinaliza futuros, na rede de ciência e tecnologia disponível na sociedade e nos movimentos sociais em defesa de projetos que associam as soluções exigidas por essas questões à qualidade social da vida coletiva no país" (BRASIL, 2002).

- Projeto institucional das escolas do campo. O Art. $4^{\circ}$. estabelece que tal projeto deve ser a "expressão do trabalho compartilhado de todos os setores comprometidos com a universalização da educação escolar com qualidade social", constituindo-se "num espaço público de investigação e articulação de experiências e estudos direcionados para o mundo do trabalho, bem como para o desenvolvimento social, economicamente justo e ecologicamente sustentável" (BRASIL, 2002).

- Proposta pedagógica das escolas do campo, sinalizada no Art. $5^{\circ}$. como aquela que garante o respeito às "diferenças e o direito à igualdade [...]", contemplando "a diversidade do campo em todos os seus aspectos: sociais, culturais, políticos, econômicos, de gênero, geração e etnia" (BRASIL, 2002).

- Calendário escolar/tempos de aprendizagem. Em seu Art. $7^{\circ}$., as Diretrizes estabelecem que "é de responsabilidade dos respectivos sistemas de ensino, através de seus órgãos normativos, regulamentar as estratégias específicas de atendimento escolar do campo e a flexibilização da organização do calendário escolar, salvaguardando, nos diversos espaços pedagógicos e tempos de aprendizagem, os princípios da política de igualdade".

- Gestão da escola. O Art. 10 das Diretrizes estabelece que "o projeto institucional das escolas do campo garantirá a gestão democrática, constituindo mecanismos que possibilitem estabelecer relações entre a escola, a comunidade local, os movimentos sociais, os órgãos normativos do sistema de ensino e os demais setores da sociedade". O Art. $11^{\circ}$., por sua vez, vem confirmar a gestão democrática enquanto paradigma nas escolas do campo ao definir que, "os mecanismos de gestão democrática [...] contribuirão para consolidação da autonomia das escolas, o fortalecimento dos conselhos que propugnam por um projeto de desenvolvimento que torne possível à população do campo viver com dignidade e para a abordagem solidária e coletiva dos problemas do campo, estimulando a autogestão no processo de elaboração, 
desenvolvimento e avaliação das propostas pedagógicas das instituições de ensino" (BRASIL, 2002).

- Em relação à formação de professores, as Diretrizes estabelecem em seu Art. 13 as especificidades da formação dos professores que vão atuar nas escolas do campo, destacando a base complementar que devem orientar os cursos de formação para este fim. Desse modo, definem que a formação de professores para o exercício da docência nas escolas do campo deverá contemplar: "estudos a respeito da diversidade e o efetivo protagonismo das crianças, dos jovens e dos adultos do campo na construção da qualidade social da vida individual e coletiva, da região, do país e do mundo" e "propostas pedagógicas que valorizem, na organização do ensino, a diversidade cultural e os processos de interação e transformação do campo, a gestão democrática, o acesso ao avanço científico e tecnológico e respectivas contribuições para a melhoria das condições de vida e a fidelidade aos princípios éticos que norteiam a convivência solidária e colaborativa nas sociedades democráticas". Destacam a necessidade de um currículo orientado para as escolas do campo a partir de suas especificidades, bem como concepções de formação de professores que formam educadores do campo para atuar como intelectual orgânico no interior da escola e fora dela para consolidação da Educação do Campo (BRASIL, 2002).

Consideramos que uma gestão democrática, luta para defender os ideais de um lugar e materializa concepção de gestão preocupada com o desenvolvimento da comunidade escolar e dos educandos que a compõem e é de fundamental importância a participação de toda a comunidade escolar nas decisões da escola, pois assim podemos construir um espaço de diálogo, discussão, troca de saberes e valores.

A expressão gestão democrática é por natureza plurissignificativa, seja ao nível das representações sociais e dos discursos de todo tipo (político, administrativo, pedagógico e até mesmo acadêmico), seja ao nível das práticas. O nosso ponto de vista é de que na prática, tal ambigüidade e oscilação semântica têm sido aproveitadas freqüentemente por diferentes forças e setores (desde logo pela administração central e pelos professores e suas organizações sindicais), servindo diferentes objetivos, interesses e estratégias (LIMA, 1998, p. 252).

Esse conceito legal obriga, em certa medida, as escolas a adotarem o princípio democrático, ao menos em forma de documento, o que é um fator contribuinte para a plurissignificação, como aponta Lima (1998). Ao se falar de gestão democrática, deve-se entender o conceito amplo de gestão, que, de acordo com Libâneo et al. (2008), caracteriza-se segundo "a atividade pela qual são mobilizados meios e procedimentos para se atingir os objetivos da organização, envolvendo, basicamente, os aspectos 
gerenciais e técnicos administrativos. Sendo assim, é sinônimo de administração" (LIBÂNEO et al., 2008, p. 101).

O conceito de gestão está associado ao fortalecimento da democratização do processo pedagógico, a participação de todo o corpo escolar de maneira responsável por todas as decisões, e na sua efetivação, com a expectativa de resultados educacionais significativos. A gestão se caracteriza pela relevância do reconhecimento da participação consciente das pessoas nas tomadas de decisões sobre orientações e planejamento do seu trabalho.

Com a Constituição Federal de 1988 e a LDBEN (Lei de Diretrizes e Bases da Educação Nacional), de 1996, afirmando a inclusão da gestão democrática na educação pública brasileira, o termo "administração escolar" foi substituído por "gestão democrática". Considerando a LDBEN 9.394/96 de fundamental importância para o âmbito da gestão democrática, a mesma não apresenta uma definição precisa para tal termo.

A concepção democrática, em construção no contexto escolar, é resultado do olhar sensível dos educadores, com o propósito de mobilizar os sujeitos envolvidos no universo escolar na perspectiva da participação e na tomada de decisões, o que reflete não só a preocupação do gestor, como do professor e todos aqueles responsáveis por mobilizar toda a comunidade escolar para uma efetiva participação na vivência dos projetos e políticas implementados no cotidiano da escola.

Nesse sentido, a convivência democrática no interior da escola é o reflexo do compromisso da comunidade escolar em ampliar os espaços de participação dos diversos segmentos escolares (professores, funcionários, gestores, pais e alunos) na melhoria da educação pública brasileira. Para administrar uma escola, são necessárias inúmeras competências, e saber trabalhar com essa diversidade é um grande desafio para o gestor escolar. Segundo Libâneo (2004),

Uma escola bem organizada e gerida é aquela que cria e assegura as melhores condições organizacionais, operacionais e pedagógica -didática de desempenho profissional dos professores de modo que seus alunos tenham efetivas possibilidades de serem bem-sucedidos em suas aprendizagens (LIBÂNEO, 2004, p. 63).

A gestão escolar necessita fomentar a participação e o comprometimento das pessoas implicadas no processo educacional da escola. Contudo, o processo educativo não pode estar desvinculado de tudo o que ocorre fora da escola, em especial no ambiente familiar. Até para que a escola possa bem desempenhar sua função de levar o 
aluno a aprender, ela precisa ter presente a continuidade entre a educação familiar e a escolar, buscando formas de conseguir a adesão da família para sua tarefa de levar os educandos a desenvolverem atitudes positivas e duradouras com relação ao aprender e ao estudar.

A participação da população na escola ganha sentido, assim, na forma de uma postura positiva da instituição com relação aos sujeitos que ela atende, em especial aos pais e responsáveis pelos estudantes, oferecendo ocasiões de diálogo, de convivência verdadeiramente humana, em suma, de participação na vida da escola.

Ao longo da história do Brasil, o debate por uma política educacional que dialogasse os conteúdos, finalidades e a realidade campesina, constitui-se em um processo demorado e árduo, que envolve pressão por parte dos movimentos sociais, expressivamente o Movimento dos Trabalhadores Rurais Sem Terra (MST), exigindo do Estado, iniciativas na oferta de educação pública de formação de profissionais para trabalharem nas escolas localizadas no Campo, na busca por uma educação pública que valorize a identidade e a cultura dos povos do campo, numa perspectiva de formação humana e de desenvolvimento local. Nesse sentido, compreende-se que a gestão das escolas do campo deve ser alicerçada nos ideários e nas necessidades que fazem parte desse contexto.

Nas escolas e nos sistemas de ensino a gestão democrática tem por objetivo envolver todos os indivíduos na construção de proposta coletiva de educação, onde os processos de gestão da escola vão além da gestão administrativa, onde envolvem ações que procurem estimular a participação de diferentes segmentos e sendo necessária uma articulação nos aspectos financeiros, pedagógicos, administrativos, buscando atingir um objetivo específico, o qual é promover uma educação de qualidade "que abranja os processos formativos que se desenvolvem na vida familiar, na convivência humana, no trabalho, nas instituições de ensino e pesquisa, nos movimentos sociais e organização da sociedade civil e nas manifestações culturais" (BRASIL, 1996, art. $1^{\circ}$ ).

É sabido que tanto na sociedade como nas escolas, se participamos dos processos de planejamento e de tomadas de decisões, exercemos o direito e o dever de cidadãos, construindo, assim, e ocupando os espaços de cidadania, pois, nossas iniciativas de participação transformam ou reproduzem a realidade que nos cerca, e ao mesmo tempo nos ajudam a desenvolver novas capacidades e habilidades para a construção da democracia ou para reforçar práticas autoritárias de exclusão. 
Assim, podemos analisar que uma gestão democrática nas escolas do campo consiste em uma prática educativa que contribua efetivamente para o desenvolvimento das relações sociais do campo, respeitando e compreendendo as múltiplas identidades que o compõem, motivando assim toda a comunidade no desenvolvimento da unidade escolar, a qual é um "símbolo cultural" onde há elementos de coletividade, laços de solidariedade e participação, o que pode concretizar o processo de gestão democrática da escola.

\begin{abstract}
A construção da escola democrática constitui assim um projeto que não é seque pensável sem a participação ativa dos professores e alunos, mas cuja realização pressupõe a participação democrática de outros setores e o exercício da cidadania crítica de outros autores, não sendo, portanto, obra que possa ser edificada sem ser em co-construção (LIMA, 2002, p. 42).
\end{abstract}

A participação da comunidade escolar nas decisões pode construir um espaço de diálogo, discussões e troca de ideias e valores, demonstrando, assim, uma gestão preocupada com o desenvolvimento e as dimensões sociais das quais o campo se compõe. É de fundamental importância que nas escolas do campo os professores, alunos e comunidade consigam ter uma parceria em prol da comunidade escolar, estabelecendo um bom relacionamento dos conhecimentos científicos das aulas com a realidade vivida por cada um que compõe o campo, pois, falando de algo que os indivíduos daquele lugar vivem e conhecem, a compreensão e assimilação serão melhores.

\title{
Gestão escolar nas escolas do campo: o olhar dos sujeitos
}

Os dados das pesquisas evidenciam que a gestão escolar nas escolas investigadas é um processo complexo e que ainda se distancia muito de uma gestão escolar ancorada nas concepções e princípios da Educação do Campo, principalmente, que atenda aos fundamentos de uma gestão democrática, articulada com a comunidade escolar, comunidade externa e movimentos sociais do campo. A gestão escolar nas escolas do campo ainda é marcada por uma lógica tecnocrática e centralizadora.

Uma leitura mais cuidadosa do contexto das escolas do campo investigadas aponta para determinantes e condicionantes internos e externos que dificultam 0 exercício da gestão democrática no cotidiano dessas escolas. A cultura escolar ainda é marcada por práticas burocráticas e centralizadoras, aliada às políticas públicas de regulação de cunho gerencialista, tem colocado os professores e gestores escolares na 
condição de "expectadores e tarefeiros", uma concepção e vivência fragmentadas de participação, impossibilitado a constituição de uma cultura democrática e de um trabalho pedagógico referenciado sócio, político e culturalmente.

Ademais, as condições de infraestrutura dessas escolas, as distâncias percorridas para ter acesso a elas, a dificuldade de uma acompanhamento mais presencial e assíduo da equipe gestora (Representantes da Secretaria Municipal de Educação, Diretor e Coordenação Pedagógica), o trabalho solitário dos professores, a ausência de uma cultura docente dos professores do campo, a ausência de uma formação mais específica para os professores que atuam nas escolas do campo, formas de planejamento ainda centralizadoras, descrédito quanto aos saberes dos professores em detrimento dos especialistas, currículo imposto, políticas de accountability e ranqueamento, dificuldade de mobilização da comunidade para uma participação mais atuante nos processos que envolvem a escola e a construção e materialização efetivado do seu Projeto Político Pedagógico, têm dificultado a gestão escolar na perspectiva da Educação do Campo. Esses aspectos acima descritos são apontados nas falas dos professores:

[...] uma dificuldade muito grande que a gente teve foi na elaboração do PPP, que reunia todo mundo. [...] tinham vezes que o povo estava tão cansado porque o documento é extenso. [...] as pessoas não se sentem parte da escola, elas podem visitar a escola, só vem na escola quando são chamadas para uma reunião. [...] Mas falando da participação que eu tive [participando] na construção do PPP do outro Núcleo, que foi padronizado todos os Núcleos [...] Se é uma participação como diz a burocracia dos autores que defendem o PPP, eles estabelecem lá como é que deve ser feito o PPP. O PPP foi construído da seguinte maneira: teve reunião com os professores, reunião com os pais. Agora, nada muito produtivo. Eram reuniões só para cumprir mesmo aquele cronograma. [...] então, na questão dos professores eu via também pouco engajamento. Porque era um tempo a mais que o professor tinha que ter para fazer aquilo. E muitos já ficavam agoniados: "Vamos acabar logo com isso! " E não tinha aquela participação. Foi uma elaboração, digamos assim, que teve uma participação desses segmentos, dos pais, dos professores, da coordenadora, da diretora, mas no sentido de sistematizar essas informações (GIRASSOL, Entrevista, 2016).

[...] quando eu vejo toda a conjuntura que é ser professor, eu acho que não precisa a gente estudar tanto, não. Para que estudar tanto, para ser executor de tarefa? Gente, é verdade! Dá uma receita para a gente e anula tudo o que a gente sabe, anula todo o conhecimento, anula tudo o que você aprendeu, anula tudo! "É isso aqui. É isso aqui!" É assim que eu me sinto. Eu acho que eu estudei para nada, porque qualquer pessoa poderia chegar lá e fazer o trabalho que eu estou fazendo, seguindo aquela receita. Então, muitas vezes, eu já me senti nesse lugar: a minha formação foi para quê mesmo? Adiantou o que, se não é considerada. Se ninguém me considera apto para dizer, por exemplo, o que ensinar, o que trabalhar. Essa é a realidade (GIRASSOL, GF, 2016). 
O diálogo, na verdade, é quase escasso. Não há. Eu gostaria que tivesse momento de formação também nas coordenações. Se resume à socialização de atividades, principalmente as avaliações (TULIPA, Entrevista, 2016).

O conteúdo é apresentado pela Secretaria de Educação. E a gente segue - Plano de Curso que é determinado pela Secretaria de Educação (JASMIN, Entrevista, 2016).

[...] o currículo é imposto - para você pensar nos conteúdos que não falam a realidade campesina. [...] E aí eu vejo a questão da invisibilidade das identidades campesinas, nesse sentido, porque são negadas a todo o tempo (TULIPA, GF, 2016).

Os professores enfatizam as condições reais de trabalho no "chão" da sala de aula, com as dificuldades com que se deparam os professores todos os dias no exercício da docência. Tais dificuldades muitas vezes são ignoradas pela equipe de gestão, que exerce uma cobrança contínua sobre os professores, por índices e resultados, que causa muitas vezes uma sensação de impotência e solidão diante da realidade e da construção de possibilidades para superar as condições adversas de trabalho e conseguir realizar um trabalho pedagógico de qualidade.

\begin{abstract}
Mas quer saber o que é que acontece? É o professor que está lá no chão da sala de aula, que se depara com aluno que não quer fazer atividade; se depara com aluno, às vezes, agressivo; se depara com adolescente que está revoltado e que você tem que controlar aquela situação para depois você dar aula. E que você tem que apresentar os resultados, porque no final da unidade temos um Conselhos de Classe que a coordenadora apresenta as estatísticas de aprovação e reprovação: "Olha, aquele índice está assim e assim. "E quando você olha aquele índice de reprovação, você também se assusta. Aí, o que é que eu posso fazer? A gente fica com essa angústia. [...]. Essa angústia de que às vezes você se sente impotente ou então, o que é que eu posso fazer? Às vezes, quando estou em casa, durmo pensando nos meus alunos e não consigo dormir. O que é que eu posso fazer? Porque está aqui na minha mão, essa situação está nas minhas mãos. Sou eu quem tenho que fazer diferença na vida desse aluno. Mas eu estou lá. É a Secretaria que está lá do outro lado? São os outros? Não. Eu estou só. Sou eu quem tenho que apresentar esse resultado; sou eu quem tenho que entender o meu papel e a minha responsabilidade. $E$ aí você ter a convicção do que você quer, porque se você não ter, não consegue fazer nada (GERBERA, GF, 2016).
\end{abstract}

Ao falarem suas percepções sobre o trabalho dos professores que atuam nas escolas do campo, os professores investigados enfatizam, no conjunto das respostas obtidas nas diferentes técnicas de pesquisa (questionário, entrevista e grupo focal), elementos para pensar os processos de regulação do trabalho docente e da gestão do pedagógico. Termos como comando, cobrança, responsabilização por resultados, 
solidão, desrespeito, adoecimento, culpabilização, falta de condições de trabalho, dentre outros, constituíram os termos mais recorrentes e associados ao trabalho do professor. Os professores também fazem críticas ao desrespeito do saber do professor e da influência dos especialistas na condução e determinação do trabalho pedagógico, o que o coloca na condição de um mero tarefeiro e executor de procedimentos; à falta de processos formativos que deem conta das demandas do cotidiano de seu trabalho; e à falta de um acompanhamento pedagógico por parte da gestão municipal e da gestão da escola. Esses fatores, segundo os professores, geram muita angústia, afetando o seu emocional, como também, têm contribuído para o adoecimento do professor e falta de perspectivas deles diante da profissão.

\begin{abstract}
A história deve ser contada de baixo para cima. E não de cima para baixo. Quem está no chão da escola somos nós. E aí [o especialista vem] de fora para usar palavras ditas acadêmicas, para falar o que a gente sabe muito bem. [...]. Porque o pessoal vem de fora, é pago para falar o que a gente já sabe muito bem de onde fala, são os problemas da educação [do município]. Isso angustia, não tem professor que não adoeça (TULIPA, GF, 2016).
\end{abstract}

E aí quando eu vejo os cursos vindos de fora, por pessoas às vezes que não conhecem a realidade cotidiana da gente...[...] que podem ter um discurso muito bem elaborado, muito bem pertinente, mas é algo que não é da realidade do aluno. Pode ser pertinente para ele, mas para mim e para o meu aluno não é. Para meu aluno, sou eu quem conheço ele, sou eu que sei como ele aprende e o que vai surtir efeito (JASMIN, GF, 2016).

[...] traz gente de fora para dizer aquilo que a gente já sabe, para falar aquilo que a gente está dizendo todo dia, mas que não é validado, não é ouvido aquilo que o professor fala (GIRASSOL, GF, 2016).

Então, autonomia, a gente não tem. Fica mesmo atrelado a questão do plano de curso sempre. [...] A gente se questiona. E o nosso plano de curso também é para moldar o aluno que eu quero. Não é o sujeito que participa, que seja de luta, que possa se organizar ali no campo para estar reivindicando seus direitos. [...] E outra coisa: que se eu tivesse autonomia, não teria Prova Brasil. Poderia escolher o programa que realmente fosse de acordo com minha realidade. [...] para mim, o professor autônomo é esse (TULIPA, entrevista, 2016).

Destaco aqui também a dificuldade de exercer a docência no contexto das CM que, por falta de uma política pública específica e pelas condições de trabalho singulares deste contexto, acabam sendo esquecidas pela gestão municipal. A falta de apoio pedagógico aos professores que lá atuam torna o trabalho docente cada vez mais precarizado e intensificado, fazendo com que os docentes recorram aos seus saberes tácitos e experienciais para dar conta da dinâmica da multissérie. 
É bem essa questão, que o " $x$ " da questão é o professor ser ouvido, porque falando a gente já está, a gente sempre externaliza quais são os problemas. Os problemas são conhecidos por eles que estão lá. Se você for perguntar a Secretária de Educação, será que ela não tem noção de como funcionam as classes multisseriadas? Nas formações que a gente vai, o tanto que a gente fala do que precisa, todo mundo já sabe do que precisa. Mas o que está faltando fazer é acontecer. [...] O que eu ia comentar era justamente isso. [A colega] comentou: está há três anos em classe multisseriada. Eu também. E a gente já está tendo noção dos problemas. [...] e nada está sendo feito (ROSA, GF, 2016).

Bolson (2012) ainda enfatiza o poder sutil e sedutor das atuais políticas educacionais que tem levado os professores a assumirem de forma irrestrita as orientações, as formas de regulação dessas políticas, contribuindo assim para um certo conformismo diante da situação em que se delineia o trabalho docente na atualidade, bem como o enfraquecimento das formas de resistência dos professores frente às determinações dessas políticas. E por fim, destaca que o exercício docente tem sido atravessado pelo individualismo e solidão, impedindo a prática do diálogo, cooperação e reflexão coletiva, deixando-os mais vulneráveis às inferências do poder político central. Portanto, ela sublinha que a valorização da docência implica a garantia de processos de autonomia, entendida por ela como a capacidade de tomar decisões sobre os problemas profissionais da prática. Por isso, a autora insiste na necessidade de que se "instale entre os docentes a capacidade de reflexão em grupo, a instauração efetiva de um processo coletivo capaz de regular ações, juízos e decisões sobre o ensino" (BOLSON, 2012, p. 14). O conjunto das respostas dos professores aponta que na conjuntura atual o trabalho docente é marcado pela solidão; é um trabalho solitário, difícil, árduo, justamente pela imposição de pacotes prontos, responsabilização por resultados e muita cobrança.

O ponto principal é a falta de respeito para com o professor. [...] porque a gente tem que lutar pelo direito a ter direito. [...] é a questão das cobranças que são inúmeras, a questão da falta de respeito está aí. Essa questão do adoecimento é notória. [...] então, que responsabilidade estão tendo com a educação? Então, isso deixa a gente angustiado, porque a gente está pensando na educação que está lá, que recebe tudo nas caixas dos peitos para dar conta. Então, essa cobrança no dia a dia, essa ação-reflexão-ação que não tem, ninguém dialoga com a gente para estar nos ajudando. A gente se sente sozinho. Na solidão, realmente (TULIPA, GF, 2016).

As falas dos professores denunciam a ausência de um acompanhamento mais sistemático por parte da SEC e da gestão escolar quanto às questões relacionadas ao pedagógico, apesar da imposição de uma rotina previamente estabelecida pelo órgão central. O que dificulta muito o trabalho do professor pela falta de acompanhamento, 
formação e um suporte pedagógico mais sistemático para atender as questões que emergem no cotidiano de sua sala de aula.

Primeiramente, é necessário compreender que as funções de um Coordenador nem sempre estão bem estabelecidas, o que o leva a realizar outras atividades, as quais poderiam ser realizadas por outras pessoas, e, assim, acumulando tarefas e se sobrecarregando, o que o acaba impedindo de exercer suas reais funções. Cabe ressaltar que a Coordenadora nas suas ações tem muita dinâmica, orienta o melhor possível o trabalho coletivo, indica alternativas, apresentando ideias, promovendo ações e dando sugestões de inovar e renovar as práticas pedagógicas. Sobretudo, fornece bases teóricas para guiar a reflexão sobre as práticas.

Geralmente, um Diretor Escolar e um Coordenador Pedagógico atendem um universo de várias escolas, o que dificulta um acompanhamento mais próximo e diário aos professores e à escola como um todo. Na maioria dos casos, no município pesquisado, as escolas recebem apenas uma visita semanal da equipe de gestão escolar, o que torna o trabalho desses professores cada vez mais solitário, muitas vezes tendo que responder por questões que são de competência da SEC, da Direção Escolar e Coordenação Pedagógica.

Observamos que, para conseguir dar conta dessas demandas, a Coordenadora Pedagógica tem que ir além do conhecimento teórico para acompanhar o trabalho pedagógico e estimular os professores, e para isso são necessárias percepção e sensibilidade para identificar as necessidades dos alunos e professores. Necessita também se manter sempre atualizada, buscando fontes de informações e refletindo sua prática. É importante também que se propicie a esses professores apoio, estimulando-os e Ihes dando uma assistência prática, visitando as salas de aula, movimentando-se pela escola, mantendo conversas informais com toda a comunidade escolar.

Os dados apontaram que a equipe gestora tem uma preocupação com a construção de um ambiente democrático e participativo, onde existe um incentivo à produção do conhecimento, tendo como articuladora a equipe gestora, com o intuito de tornar a escola um ambiente prazeroso de formação docente. Contudo, é perceptível que diante da complexidade do modelo de gestão existente nas escolas do Campo, por mais que se deseje realizar uma gestão com participação da comunidade, é complicado, pois o distanciamento da equipe gestora, a qual se encontra na maioria das vezes na Secretaria de Educação, toma proporções desagradáveis, diante de situações em que seria necessária a presença da equipe gestora no local. 
Sabemos que a Coordenação Pedagógica é o espaço reservado para organizar o trabalho pedagógico nas instituições de ensino e, para isso acontecer, faz-se necessária a presença do líder que atua na função. No entanto, esse momento, o qual deveria ser descontraído e cheio de ideias e projetos, torna-se desgastante, o profissional fica em salas apertadas, pois a Educação do Campo não possui um espaço reservado só para suas demandas, tendo que dividir o mesmo com vários segmentos, e sem falar na pobreza de material adequado para efetuar pesquisas. E esse momento fica reservado apenas para sugestões e recados, obrigando, assim, os professores a outra carga horária em sua casa para, de fato, realizarem o planejamento pedagógico. Sem contar com a demanda dos professores das classes multisseriadas, que é ainda maior, tendo que pesquisar e realizar vários planos para uma mesma sala sem ferramentas de pesquisa.

Ressaltamos que a dificuldade de um acompanhamento mais qualitativo e pontual, por parte da Direção e Coordenação Pedagógica, dá-se em virtude do quantitativo de escolas que compõem um Núcleo Escolar para serem acompanhadas por um único Diretor e Coordenador pedagógico, como também a inexperiência dos professores que exercem a função de coordenação pedagógica. Outra professora, que já atuou no passado como Coordenadora Pedagógica, destaca a precariedade das condições didático-pedagógicas ofertadas aos professores para desenvolverem um bom trabalho em sala de aula.

Também percebo que é complicado nós estarmos em um Núcleo com seis escolas e termos apenas uma Coordenadora para dar conta de tudo quanto é coisa. Porque eu já trabalhei na função de coordenadora e trabalhar em um Núcleo com seis escolas - foi sete na que eu estava, mas nessa realidade são seis - e você fazer visitas, você, às vezes, se percebe mais agindo na parte administrativa, porque o tempo é curto [para] você sair de carro visitando. O tempo que você leva até se deslocar até a escola já é muito tempo. Você chega e, às vezes, não dá tempo de você fazer um trabalho como você gostaria, dar uma devolutiva a esse professor. Mas essa questão a gente não está tendo. Só estamos com uma Coordenadora, apenas. E não estamos tendo contato pedagógico. A gente não percebeu ainda. Não desfazendo da pessoa, da profissional que está lá, mas o que está acontecendo enquanto pedagógico, a gente, professor, poderia dar conta (TULIPA, entrevista, 2016).

Essa questão foi também pontuada pela Coordenadora Pedagógica do Núcleo 6 durante a entrevista:

$\mathrm{Na}$ Educação do Campo isso é totalmente complicado. Como minha Diretora mesmo, ela tem 6 escolas. Um Núcleo com 6 escolas e a semana com 5 dias de aula. Então, fica complicado ela estar na escola também acompanhando esse papel pedagógico. E para estar em todas as escolas não é fácil também. Então, falta ainda essa questão do Diretor ter esse envolvimento com o pedagógico, saber o que é que tem que ser 
trabalhado na semana; sabe, mas não se envolve tanto. (VIOLETA, entrevista, 2016).

As dificuldades enfrentadas atualmente pelo Coordenador não são diferentes dos tempos anteriores. O modelo de organização do trabalho pedagógico existente nas Escolas do Campo é o nucleado. No município investigado, as escolas do campo estão organizadas por Núcleos Escolares ${ }^{4}$ para facilitar a administração e gestão pedagógica das mesmas. No total são cinco (5) Núcleos de escolas do campo, cada um deles contendo entre quatro e seis unidades escolares ${ }^{5}$. A divisão das escolas por Núcleo tem como critério a região geográfica nas quais as escolas estão localizadas. A nucleação foi a solução encontrada pela Secretaria Municipal de Educação para dar mais assistência e organização às escolas do campo, garantindo as presenças de diretora e coordenadora pedagógica.

Eu e a diretora tentamos nos articular para que a gente consiga contemplar o maior número de escolas possível, nós não vamos para a mesma escola no mesmo dia, ficamos em espaços diferentes, esse distanciamento é um dos fatores dificultadores do acompanhamento (COORDENADORA PEDAGÓGICA, entrevista, 2018).

Durante as observações ficou nítida também a angústia por parte dos professores, os quais desejam uma Direção e Coordenação mais próximas e do Coordenador e Gestor por não poderem, de fato, exercer suas funções com mais qualidade.

Assim, a professora Tulipa complementa que diante dessa situação de "ausência" desse acompanhamento pedagógico, os professores acabam tendo uma margem de autonomia para irem desenvolvendo seu trabalho pedagógico, não uma autonomia conquistada, mas permitida pelas condições de trabalho dadas. Sinaliza também que a falta de acompanhamento pedagógico faz com que os professores construam um trabalho tipo "artesanal", ancorados em seus conhecimentos tácitos e experienciais, justamente pela falta de uma formação específica para realização de um trabalho diferenciado nas escolas do campo, o que a leva a questionar se realmente está desenvolvendo seu trabalho pedagógico de forma coerente, em virtude das condições de trabalho ofertadas pela gestão municipal da educação.

Acho que a gente fica apagando incêndio, não sei. É angustiante, porque a gente não sabe se está fazendo o trabalho certo. Quer dizer, na verdade,

\footnotetext{
${ }^{4}$ Este formato foi definido no final dos anos 1990, após ensaios experimentados desde a década de 1980.

${ }^{5}$ No início da implantação dos Núcleos Escolares, na década de 1990, cada Núcleo possuía maior número de escolas, mas com a diminuição demográfica da população rural e o fechamento de unidades escolares, o número de escolas por núcleo vem se reduzindo.
} 
eu não estou fazendo o trabalho certo. Eu estou fazendo o que eu posso fazer, de acordo com as possibilidades, com a falta de formação que a gente precisa estar estudando muita coisa, até pela questão dessa proposta diferenciada, um currículo diferenciado da Educação do Campo. [...] Mas ainda não é o ideal (TULIPA, entrevista, 2016).

A Coordenadora Pedagógica, é concebida como uma das protagonistas que compõem o coletivo da escola, para coordenar, direcionando suas ações para a transformação, situação na qual precisa estar consciente que seu trabalho não se dá isoladamente. Portanto, a coordenadora reconhece a importância de discutir com o professor suas ações com os alunos, ela considera necessário conhecer como ocorrem nas salas de aula as relações de ensino e aprendizagem, principalmente, no que se refere ao modo como o professor encaminha a interação da criança com o conhecimento. Percebe-se que a Coordenadora procura levar os educadores à conscientização de uma nova postura, acreditando na possibilidade de transformar a realidade e também acreditando na escola como um espaço de transformação social.

Para tanto, precisamos pensar a formação de educadores e educadoras do campo para além dos espaços formais, a educação do campo é uma prática social, e como tal não se limita aos muros das escolas, ela está imersa na comunidade e comunga dos problemas sociais que a mesma enfrenta. Assim, há que se pensar na formação de educadores que dê conta de abranger também os espaços não formais de educação, permitindo-os interagir nos espaços extraescolares.

Uma Diretora que participou da pesquisa, demonstra que empenho e persistência, principalmente a respeito da preocupação com a aprendizagem dos alunos, assim como outras questões administrativas, tais como o abandono, a frequência, as faltas e a não reprovação, pois a função é "gerir desde contas, corpo docente e até mesmo zelar pelas relações interpessoais" (DIRETORA ESCOLAR, entrevista, 2018).

Sendo assim, analisamos que a Diretora se mostra preocupada não somente com as questões administrativas, mas também com as questões de aprendizagem, formação dos professores, desempenho dos alunos, com o tempo administrado nas classes multisseriadas, para que não haja perdas para os alunos, com o trabalho coletivo entre os profissionais, e nas relações em geral entre todos os funcionários. Afirma também:

Também somos os responsáveis pela administração do espaço (dos espaços no meu caso), obedecendo as normas e diretrizes da SEMED, acompanhar $o$ desenvolvimento pedagógico $e$ as questões administrativas, auxiliar na elaboração dos projetos e aproximar a comunidade da escola ou a escola da comunidade (DIRETORA ESCOLAR, Entrevista, 2018). 
Percebe-se que é uma Direção que também se preocupa com a parte burocrática de seu funcionamento. Ela, por muitas vezes, não tem tempo para o "fazer" pedagógico, pois sempre está exercendo o papel administrativo, o qual toma bastante tempo do cotidiano escolar, e não permite que a Direção assuma o seu papel das organizações pedagógicas.

Diante dessa situação, na qual o Diretor tem muitas demandas burocráticas, percebemos que sempre que possível ela está em constante contato com a Coordenadora na SEMED. Pois a estratégia utilizada por elas, a Diretora e Coordenadora, para se fazerem presentes em todas as escolas do Núcleo, não permite que as duas estejam na mesma escola no mesmo dia e horário. Sendo assim, elas buscam alternativas para resolver as situações nos encontros na SEMED, uma vez que as Escolas do Campo não possuem um espaço direcionado para as demandas dessas escolas.

Compreendemos que o gestor é um profissional que exerce um papel de extrema importância nesse processo, pois ele, juntamente com a equipe pedagógica, organiza o trabalho pedagógico, além de conduzir as diversas demandas relacionadas aos recursos financeiros, planejamentos estratégicos, conhecimentos administrativos e pedagógicos da escola. Na visão da Diretora, o bom gestor é aquele que tem um bom relacionamento com todos da comunidade escolar, valorizando-os e estimulando-os para a melhoria na educação. Ainda sobre a Função do Gestor Escolar, a Diretora, quando questionada sobre as características do Gestor, afirma:

O bom gestor é aquele que desenvolve a sua função profissionalmente, mas que está disposto a ter um bom vínculo com todos os envolvidos na educação. $E$ aquele também que deve estar apto a perceber o valor e a importância de cada discente, docente, funcionário, comunidade e todos envolvidos numa luta conjunta para melhoria da educação (DIRETORA ESCOLAR, entrevista, 2018).

Observou-se que a Gestora, devido à sobrecarga no desenvolvimento de suas funções, acaba se dedicando mais às tarefas administrativas e organizacionais, correndo o risco de se perder tanto em relação à questão administrativa quanto em relação às questões pedagógicas, situação na qual essas condições burocráticas não oportunizam a autoavaliação do processo de elaboração das propostas pedagógicas, as quais valorizam a diversidade campesina e a transformação do Campo. 
Dessa forma, muitos professores acabam, muitas vezes, assumindo as funções da Direção e Coordenação Pedagógica, justamente por todas as dificuldades aqui apontadas para gestar as escolas do campo, no âmbito administrativo e pedagógico, como é enfatizado nas falas dos professores:

Eu me sinto, tem horas, uma máquina. Eu tenho que chegar na escola, correr contra o tempo, dar todo o conteúdo, passar atividade para casa, porque se não for atividade para casa os pais questionam. Eu me sinto o tempo todo culpada, porque eu fico querendo fazer além do que é o meu papel enquanto professora, resolver o problema do lado de fora da escola; resolver o problema que a cozinheira tem na cozinha; resolver o problema do motorista, porque atrasou, porque o pneu furou, porque aconteceu um imprevisto; você tem que ficar atento porque a criança não chegou, está em cima do horário, para procurar saber, mandar alguém ir lá ver o que foi que houve (JASMIN, GF, 2016).

É porque a gente fica preocupada demais em fazer as coisas, arcando com nosso compromisso. Mas talvez se nós nos ocupássemos da nossa função de educador mesmo e não cumprisse a tarefa do outro, o pessoal ia sentir. Se faltou merenda para o aluno, é passar a situação para quem é de direito. Pode ligar: "Está faltando merenda aqui, vou liberar os alunos". Entendeu? É por isso que está desse jeito, porque a gente fica apagando esses incêndios todos, fazendo o nosso papel e o papel dos outros, e as coisas ficam tudo assim, fazendo de conta que está tudo bonito. E essas angústias mexem com a gente e aí vai para essa questão da precarização da educação. A gente não tem apoio (TULIPA, GF, 2016).

Porque, como é que eu vou resolver um problema que não está dentro da sala de aula? Mas eu preciso resolver, porque o gás acabou e preciso ir com a cozinheira buscar o botijão emprestado, porque ela não consegue trazer [sozinha]. Eu tenho que deixar os meninos na sala fazendo uma outra atividade para poder ir lá e garantir que $10 \mathrm{~h}$ a merenda vai ser servida. Se um passa mal, se um sente uma dor de barriga, se uma criança vomita na sala, eu tenho que sair para ajudar, para socorrer essa criança, e a sala vai ficar lá até a hora que essa criança estiver bem, que eu possa deixá-la na companhia só da cozinheira, enquanto chega o transporte para levá-la. Então, isso tudo tem angustiado (JASMIN, entrevista, 2016).

Entretanto, sabemos que o gestor escolar precisa não só criar espaços de discussões que possibilitem a construção de um projeto educativo preparado e experimentado por todos os segmentos da comunidade escolar, mas também é necessário solidificar tais espaços a fim de garantir que a escola cumpra seu papel social de transformação pelo conhecimento.

A partir da discussão dos dados apresentados questionamos: quais espaços existem e estão sendo construídos para que a gestão das escolas e trabalho dos professores do campo possam incorporar práticas mais democráticas, autônomas e 
participativas? Como superar os limites contradições que impossibilitam a materialidade da gestão democrática no cotidiano das esquilas do campo?

Defendemos que a Educação do Campo tem como pauta de luta incluir a questão da democratização do Estado (CALDART, 2009), portanto, o Estado defendido pela Educação do Campo compromete-se com a construção de um sistema público de Educação do Campo. As políticas públicas construídas no âmbito da Educação do Campo, sustentadas em sua materialidade de origem, passaram a responder pelas demandas das populações campesinas que foram historicamente marginalizadas quanto aos seus direitos cidadãos no âmbito do Estado, implicando um envolvimento mais direito dos sujeitos coletivos do campo no processo de correlações de força, a disputa pela educação e pela escola.

\section{Considerações}

A Gestão nas Escolas do Campo e todo o seu contexto corresponde a uma questão de profunda complexidade e que ainda carece de um melhor levantamento de suas condições de funcionamento. É preciso insistir na construção de espaços no cotidiano escolar que venham contribuir para o exercício de reflexão contínua da importância da Gestão democrática e participativa nas Escolas do Campo. Dentro dessa preocupação, coloca-se a questão das condições de trabalho dos atores escolares e de sua formação. Torna-se imprescindível oportunizar um espaço de transformação social e construção/expansão de novos conhecimentos a respeito da Gestão Democrática, no qual os sujeitos da escola se tornem a figura principal no processo de democracia, considerando-os capazes de refletir a sua própria realidade, e a partir dela, construir seus conhecimentos sob um olhar de uma gestão democrática e participativa.

A Educação do Campo tem como pauta de luta incluir a questão "da democratização do Estado, com todas ou por todas as contradições que isso encerra" (CALDART, 2009). Portanto, o Estado defendido pela Educação do Campo compromete-se com a construção de um sistema público de Educação do Campo. As políticas públicas construídas no âmbito da Educação do Campo, sustentadas em sua materialidade de origem, passaram a responder pelas demandas das populações campesinas que foram historicamente marginalizadas quanto aos seus direitos cidadãos no âmbito do Estado, implicando um envolvimento mais direito dos sujeitos coletivos do campo, no processo de correlações de força e disputa. Apontamos assim, a necessidade 
de repensar o processo da Gestão nas Escolas do Campo, articulada com os sujeitos de direito e os Movimentos Sociais do Campo.

Compreende-se também que a gestão necessita manter os esforços para que as escolas permaneçam em funcionamento e em constante transformação, até mesmo porque apenas sua existência já se constitui como exemplo de luta e resistência.

Assim, as pesquisas trazem contribuições para se pensar a gestão de um trabalho pedagógico, em que, a educação transcenda a perspectiva do conhecimento-regulação para o conhecimento-emancipação e, que responda pela Educação do Campo como um projeto e paradigma de sociedade da classe trabalhadora, que tem como pressuposto central um modelo de desenvolvimento que assegure a manutenção da vida dos povos do campo, a partir da garantia de direitos fundamentais.

\section{Referências}

BOLSON, Janaina Boniatti. As miríades possíveis do desempoderamento docente no cotidiano escolar. Trabalho apresentado no IX Seminário de Pesquisa em Educação da Região Sul (Anped Sul), 2012. Caxias do Sul-Rio Grande do Sul, Brasil. Disponível em: <http://www.ucs.br/etc/conferencias/index.php/anpedsul/9anpedsul/paper/view/90/428. > Acesso em 20 de abril de 2017.

BRASIL. RESOLUÇÃO CNE/CEB 1, DE 3 DE ABRIL DE 2002. Institui Diretrizes Operacionais para a Educação Básica nas Escolas do Campo. Disponível em:<http://portal.mec.gov.br/index.php?option=com_docman\&view=download\&alias $=1380$ 0-rceb001-02-pdf\&Itemid=30192>. Acesso em: 10 nov. 2016.

BRASIL. Lei n 9.394, de 20 de dezembro de 1996. Estabelece as Diretrizes e Bases da Educação Nacional. Diário Oficial da União, Brasília, 23 dez. 1996. Disponível em: <http://www.planalto.gov.br/CCIVIL_03/leis/L9394.htm>. Acesso em: 06 set. 2018.

CALDART, Roseli Salete. ELEMENTOS PARA CONSTRUÇÃO DO PROJETO POLÍTICO E PEDAGÓGICO DA EDUCAÇÃO DO CAMPO. Revista Trabalho Necessário, v. 2, n. 2 , 14 dez. 2004. Disponívem em:

$<$ https://periodicos.uff.br/trabalhonecessario/article/view/3644. Acesso em 15 dejaneiro de 2020.

LIBÂNEO, José Carlos; OLIVEIRA, João Ferreira; TOSCHI, Mirza Seabra. Educação escolar: políticas, estrutura e organização. 10ª ed. São Paulo: Cortez, 2012.

LIBÂNEO, José Carlos; OLIVEIRA, João Ferreira; TOSCHI, Mirza Seabra. Educação escolar: políticas, estrutura e organização. 6ª ed. São Paulo: Cortez, 2012.

LIBÂNEO, José Carlos. Organização e Gestão da escola: Teoria e prática. 5. ed. Goiânia: Alternativa, 2004. 
LIMA, Licínio Carlos. Concepções de escola: Por uma hermenêutica organizacional. In: Lima, L. C. (Org.), Perspectivas de análise organizacional das escolas (pp. 15-57). Vila Nova de Gaia-Portugal: Fundação Manuel Leão,2010.

LIMA, Licínio Carlos. Organização Escolar e Democracia Radical: Paulo Freire e a governação democrática da escola pública. 2. ed. São Paulo: Cortez; Instituto Paulo Freire, 2002.

LIMA, Licínio Carlos. A escola como organização e a participação na organização escolar. 2. ed. Braga: Centro de Estudos em Educação e Psicologia, Universidade do Minho, 1998.

MARTINS, Fernando José. J. Gestão democrática da escola do campo. Trabalho apresentado no XXIV Simpósio Brasileiro de Política e Administração da Educação, 2009. Universidade Federal do Espírito Santo - UFES, Vitória-Espírito Santo, Brasil. Disponível em:< http://www.anpae.org.br/congressos antigos/simposio2009/114.pdf.> Acesso em 24 de março de 2017.

MARTINS, José de Souza. Os camponeses e a política no Brasil. $3^{\mathrm{a}}$ ed. Petrópolis: Vozes, 1986.

PARO, Vitor Henrique. Administração escolar: introdução crítica. 16. ed. São Paulo: Cortez, 2010.

SANTOS, Arlete Ramos dos. Ocupar, Resistir e Produzir, também na Educação. $O$ MSTe a burocracia estatal: Negação e Consenso. Jundiaí: Paco Editorial, 2013.

SILVA, Ilsen Chaves da. Escolas multisseriadas: quando o problema é a solução. 2008. Dissertação (Mestrado Acadêmico). Programa de Pós-graduação em Educação da Universidade do Planalto Catarinense, Lages-SC, 2008.

SILVA, Maria Socorro. Da raiz à flor: produção pedagógica dos movimentos sociais e a escola do campo. In: MOLINA, M. C. (Org.). Educação do campo e pesquisa.

Questões para reflexão. Brasília: Ministério do Desenvolvimento Agrário, 2006. p. 60-93.

\section{SOBRE AS AUTORAS}

\section{Terciana Vidal Moura}

Doutora em Ciências da Educação pela Universidade do Minho, Graduada em Licenciatura em Pedagogia pela Universidade do Estado da Bahia-UNEB, Especialista em Metodologia do Ensino, Pesquisa e Extensão em Educação pela UNEB, Mestre em Educação e Contemporaneidade pela UNEB. Correio eletrônico: tercianavidal@ufrb.edu.br

\section{Juliane Queiróz Muniz Neri}

Mestranda do Mestrado Profissional em Educação do Campo da UFRB (PPGEDUCAMPO). Professora/Assistente de Classe do Sistema Municipal de Educação de Amargosa; integra o Grupo de Pesquisa Observale (UFRB). Correio eletrônico: juliane.muniz.neri@hotmail.com 